\title{
Cell Growth and Differentiation on Feeder Layers Is Predicted to Be Influenced by Bioreactor Geometry
}

\author{
Ching-An Peng'.† and Bernhard Ø. Palsson ${ }^{1,2, *}$ \\ 'Department of Chemical Engineering, University of Michigan, Ann Arbor, \\ Michigan 48109-2136 and ${ }^{2}$ Aastrom Biosciences Inc., Ann Arbor, Michigan \\ 48106
}

Received May 3, 1995/Accepted December 28, 1995

Tissue function is comprised of a complex interplay between biological and physicochemical rate processes. The design of bioreactors for tissue engineering must account for these processes simultaneously in order to obtain a bioreactor that provides a uniform environment for tissue growth and development. In the present study we consider the effects of fluid flow and mass transfer on the growth of a tissue in a parallel-plate bioreactor configuration. The parenchymal cells grow on a preformed stromal (feeder) layer that secretes a growth factor that stimulates parenchymal stem cell replication and differentiation. The biological dynamics are described by a unilineage model that describes the replication and differentiation of the tissue stem cell. The physicochemical rates are described by the Navier-Stokes and convectivediffusion equations. The model equations are solved by a finite element method. Two dimensionless groups govern the behavior of the solution. One is the Graetz number $(\mathrm{Gz})$ that describes the relative rates of convection and diffusion, and the other a new dimensionless ratio (designated by $P$ ) that describes the interplay of the growth factor production, diffusion, and stimulation. Four geometries (slab, gondola, diamond, and radial shapes) for the parallel-plate bioreactor are analyzed. The uniformity of cell growth is measured by a two-dimensional coefficient of variance. The concentration distribution of the stromaderived growth factor was computed first based on fluid flow and bioreactor geometry. Then the concomitant cell density distribution was obtained by integrating the calculated growth factor concentration with the parenchymal cell growth and unilineage differentiation process. The spatiotemporal cell growth patterns in four different bioreactor configurations were investigated under a variety of combinations of $\mathrm{Gz}\left(10^{-1}, 10^{\circ}\right.$, and $\left.10^{1}\right)$ and $P\left(10^{-2}, 10^{-1}, 10^{0}, 10^{1}\right.$, and $\left.10^{2}\right)$. The results indicate high cell density and uniformity can be achieved for parameter values of $P=0.01 \ldots, \ldots .1$ and $\mathrm{Gz}=0.1, \ldots, 1.0$. Among the four geometries investigated the radial-flowtype bioreactor provides the most uniform environment in which parenchymal cells can grow and differentiate ex vivo due to the absence of walls that are parallel to the flow paths creating slow flowing regions. (c) 1996 John Wiley \& Sons, Inc.

\footnotetext{
$\dagger$ Present address: StemCell Technologies Inc., 808-777 West Broadway, Vancouver, B.C., Canada V5Z $4 \mathrm{~J} 7$

* To whom all correspondence should be addressed at Dept. of Bioengineering, University of California, San Diego.
}

Key words: stem cell - bioreactor - stromal layer Graetz number

\section{INTRODUCTION}

Growth of human tissues ex vivo for cellular therapy and tissue engineering is a burgeoning topic. $2,4,19,22,25,38,40,57,58$ Bioreactors that accurately simulate the in vivo microand macroenvironment are needed for the cultivation of primary cells for basic scientific studies and for the production of a clinically meaningful number of cells for cellular therapy. Most types of primary tissue cultures contain cells that require attachment to a substratum for proper functioning. Single-pass perfusion systems composed of parallel plates have proven to be an appropriate configuration for a number of applications.

Several issues have been addressed using this bioreactor type. A number of flow chambers have been designed to investigate the effects of shear stress on cells ${ }^{13,23,28,59}$ and for studying cell adhesion, ${ }^{7,9,24,63,64}$ Parallel-plate flow chambers have also been utilized for the growth and maintenance of primary cell ex vivo for cellular therapy purposes. ${ }^{16,20,21,41,50}$ In spite of their extensive use, only a few studies have addressed the effects of the physicochemical rate processes that take place in such perfusion chambers. ${ }^{18,39}$ These analyses were based on two-dimensional Hele-Shaw fluid flow, ${ }^{52}$ and the coupled mass transport of secreted or supplied compounds was evaluated by a two-dimensional mathematical model. In addition, quite a few two-dimensional heat transfer analyses of ducts have been reported in the literature. ${ }^{55}$

Here, we show that, in thin parallel-plate flow chambers, the assumption that the bioreactor is uniform in the third spatial dimension is compromised by the fact that the concentration gradients that emanate from the side walls can exceed the hydrodynamic boundary layer, ${ }^{44}$ and that this feature can lead to nonuniform cell growth. For any bioreactor design, the flow of medium and cells has to be bounded by walls. The wall not only influences fluid flow in its vicinity but also affects the concentration distribution. Since the concen- 
tration distribution of supplied or secreted proteins inside bioreactors can be nonuniform, we may not be able to thoroughly understand the effect of either endogenously secreted or exogenously supplied protein on the cell culture by a simplified two-dimensional analysis. A complete analysis would have to take into account the three-dimensional shape effects on growth factor concentration distribution, which in turn can influence cell growth kinetics and other cell behaviors.

For cultivating many tissue types such as skin, bone marrow, or liver, stroma (or feeder layer) is important for sustaining long-term tissue cultures. ${ }^{3,16,20,21,34}$, $35,37,41,48,49$ The effect of growth factors and/or chemotactic factors secreted by stromal cells, leading to reconstitution of tissue function in ex vivo cultures, is thus expected to be significant. Therefore, the concentration distribution of secreted proteins may be prove to be a critical consideration in the design and function of bioreactor systems for tissue engineering. As a model system for studying these effects, this article focuses on the concentration distribution of endogenously secreted growth factors by a preformed stromal layer on the growth and differentiation of parenchymal stem cells.

\section{MODEL DEVELOPMENT}

To develop an integrated description of physicochemical and cell developmental dynamics, we need to first set up conceptual models that described the underlying processes (Fig. 1). Such conceptual models are based on a number of assumptions that need to be explicitly stated. The conceptual models then need to be trans-

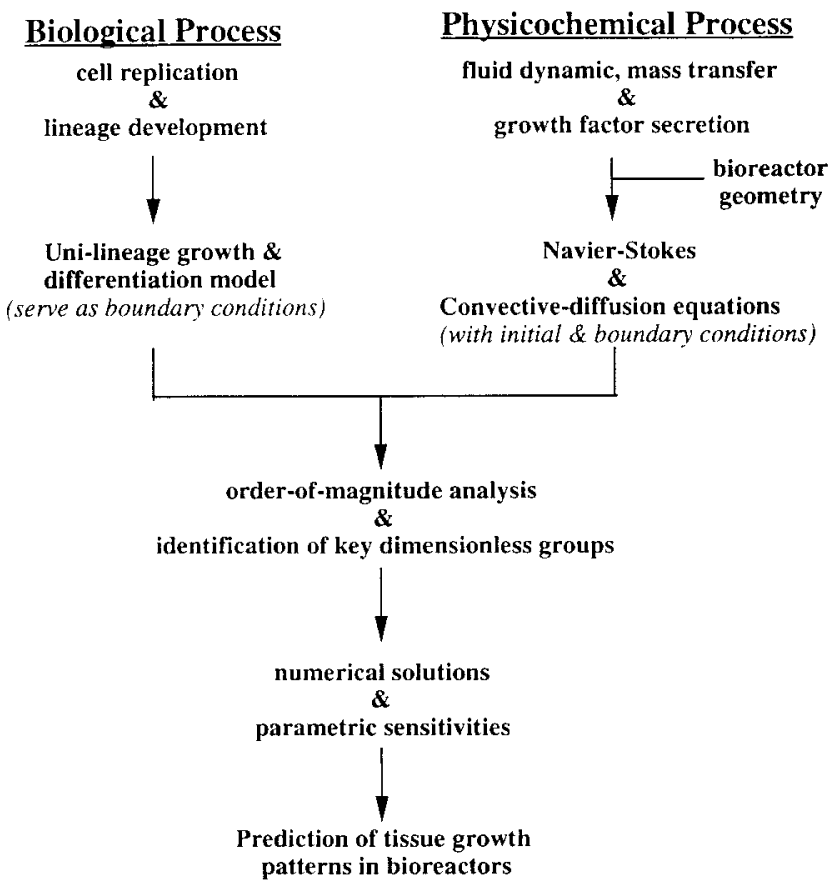

Figure 1. Structure of the modeling strategy used. lated into mathematical descriptions. The numerical values for the parameters appearing then need to be determined. Key dimensionless property ratios are then formed to predict model behavior and to aid in the interpretation of the solutions obtained. The appropriate numerical solution strategy is then implemented so that the solutions can be obtained. Order-ofmagnitude analysis is then performed to formulate the key dimensionless parameter ratios that describe critical differences in overall behavior and to provide a framework for obtaining meaningful numerical solutions. The processes just described are outlined in Figure 1 and can be executed to obtain a spatiotemporal description of tissue dynamics in parallel-plate bioreactors.

\section{Cell Development and Tissue Formation}

\section{Conceptual Model}

Rapidly proliferating tissues, such as bone marrow, ${ }^{11,17,62}$ epidermis, ${ }^{17,47,68}$ and gut ${ }^{17,45,46}$ are believed to originate from tissue-specific stem cells. Recently, it has been suggested that even quiescent tissues, such as liver ${ }^{54,56,61}$ and neural crest, ${ }^{10,60}$ harbor stem cells. Conceptual stem cell models, formulated based on extensive biological data, are thus used to describe the function of many tissues.

Stem cells are defined by two important characteristics: first, stem cells are capable of self-renewal, i.e., undergoing symmetric divisions to maintain a germinal population; second, stem cells have the potential to generate differentiated, often multilineage, progeny. The latter takes place either by an asymmetric division where one daughter cell is committed to differentiation while the other retains stem cell characteristics, or by a division where both of the daughter cells undergo differentiation. ${ }^{26}$ Therefore, the stem cells persist over time and retain the capability to generate parenchymal cells. The progeny of stem cells undergoes a series of differentiation and replication events to generate a large number of mature cells.

\section{Assumptions}

Unilineage differentiation models have been formulated to describe the differentiation process ${ }^{5,17,53,65,66,68}$ (see Fig. 2). A kinetic description of a unilineage model is based upon the following assumptions:

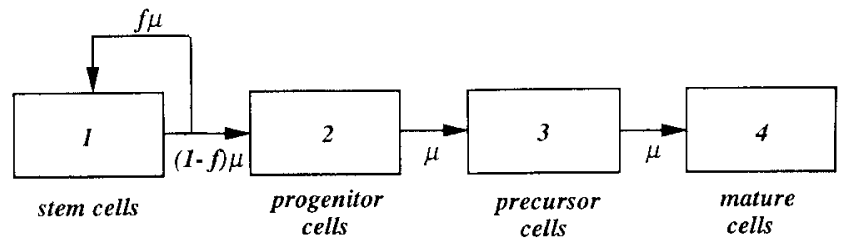

Figure 2. Schematic representation of a unilineage model for tissues derived from self-renewing stem cells. 
1. The process is viewed as a series of discrete stages through which the cells pass as they unidirectionally differentiate and proliferate.

2. The stem cells are in the first compartment. Upon division, a stem cell may self-renew or differentiate. ${ }^{62}$ The probability of self-renewal, $f$, is between 0 and 1. If differentiation occurs, the cell moves on to the next stage of differentiation; otherwise, it remains in the stem cell compartment.

3. The Monod growth model ${ }^{33}$ will be used to describe the effects of a growth-factor-derived mitogenic stimuli on the growth rate $(\mu)$. Although Monod's model was originally used to describe microbial growth in response to a limiting nutrient concentration, this model has also been successfully used to describe the mitogenic effects of growth factors. ${ }^{14}$ Furthermore, it can be used to fit many reported experimental data. ${ }^{15,27,32}$ Accordingly, the growth rate is described as

$$
\mu=\mu_{\max } \frac{C_{s}}{K_{s}+C_{s}}
$$

where $C_{s}$ is the concentration of growth-limiting factor, here taken to be stromally derived (see below); the maximal growth rate is $\mu_{\max }\left(=\ln 2 / t_{d}, t_{d}=\right.$ doubling time); and $K_{s}$ is the Monod constant at which cell growth reaches one-half of the maximum specific growth rate.

4. Fully mature cells have a wide range of life spans. For instance, granulocytic cells have a life span that is less than 1 day, whereas erythrocytes have a life span of about 4 months. ${ }^{8}$ Here, we assume that the fully mature cells do not die during the course of the ex vivo tissue growth that is being simulated. In addition, no cell death is assumed to take place in the intermediate compartments.

\section{Kinetic Model}

Based on these assumptions, a cell population balance on each compartment in Figure 2 leads to a set of dynamic equations that describe the differentiation process:

$$
\begin{aligned}
\frac{d M_{1}}{d \tau} & =(2 f-1) M_{1} \frac{\theta}{K_{s} / C_{0}+\theta} \\
\frac{d M_{2}}{d \tau} & =\left[2(1-f) M_{1}-M_{2}\right] \frac{\theta}{K_{s} / C_{0}+\theta} \\
\frac{d M_{3}}{d \tau} & =\left[2 M_{2}-M_{3}\right] \frac{\theta}{K_{s} / C_{0}+\theta} \\
\frac{d M_{4}}{d \tau} & =2 M_{3} \frac{\theta}{K_{s} / C_{0}+\theta}
\end{aligned}
$$

with the following initial conditions:

$$
\left.\tau=0 \quad M_{n}=M_{n}\right)_{0} \quad n=1,2,3,4
$$

where $\tau$ is the dimensionless time which is $\mu_{\max } t$; is the cell density; and $\theta\left(=C_{s} / C_{0}\right)$ is the dimensionless concentration of the secreted growth factor. The reference concentration $C_{0}$ is defined below.

We consider the case where the mitogenic stimulus is derived from a preformed layer of stromal cells. Stromal cells (or feeder layers) often are required to obtain tissue function ex vivo. Accessory cells are known to play a critical support role in tissue function..$^{29,36}$ The secretion of the growth factor is then described by

$$
D \frac{\partial C}{\partial n}=-K
$$

where $K$ is a product of the per-cell growth factor secretion rate and the surface stromal cell density. This system of ordinary differential equations can be integrated to determine the cell distribution at the various stages of differentiation as functions of time and the kinetic parameters of the model. It should be pointed out that if the growth factors are either consumed or degraded, then the mathematical expression for the flux balance on the cell bed needs to be modified from Equation (7) to account for these processes.

\section{Model Parameters and Their Estimated Numerical Values}

The parameters appearing in the unilineage model are $\mu_{\max } f$, and $K_{s}$. The apparent regeneration time for bone marrow in vivo is about 2 days, ${ }^{22}$ and this is closely approximated in perfusion-based bioreactor systems. ${ }^{21,41}$ For human epidermal keratinocytes, the average doubling time is about 1 day. ${ }^{48,49}$ Thus the maximal growth rates $\mu_{\max }$ are $0.35 \mathrm{day}^{-1}$ and $0.69 \mathrm{day}^{-1}$ for hematopoietic cells and keratinocytes, respectively. Under steady-state in vivo conditions, $f$ must be 0.5 . However, if expansion of stem cells takes place, $f$ exceeds $\frac{1}{2}$. Here, we use 0.6 to simulate an expanding stem cell population. The values of $K_{s}$ fall into the range of 0.05 to $5.0 \mathrm{ng} / \mathrm{mL} .^{15,27,32}$

Initial conditions must be assigned. We will use initial conditions that simulate the self-renewal, growth, and differentiation of stem cells that are present at the beginning of the culture. Thus, initially all cell compartments are assumed to be empty except for the first one. The value of the secretion rate $K$ can be obtained by direct measurement of a particular protein of interest from a known number of cells. Alternatively, its value can be obtained from the stromal cell density and the estimated maximal achievable secretion rate per cell. The latter has been estimated to be on the order of $2000-8000$ molecules/cell/s. ${ }^{51}$ Stromal cells may not be secreting at this maximum rate, and this numerical value should be considered as an upper bound on this parameter. 
Bioreactor Geometry and

Physicochemical Processes

\section{Conceptual Model}

The growth of stem cells on a performed feeder layer (or stromal layer) in bioreactors of four basic geometries will be considered. Geometries of four representative parallel-plate flow chambers and their coordinate systems are shown in Figure 3a. These geometries represent the shapes of various chambers that have appeared in the literature. ${ }^{7.20,24,50}$ The depth of all chambers was considered to be the same and was set at $0.3 \mathrm{~cm}$. By

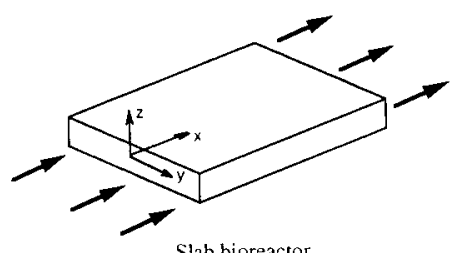

Slab bioreactor

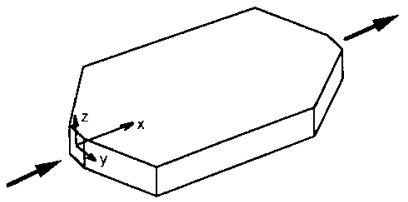

Gondola bioreactor
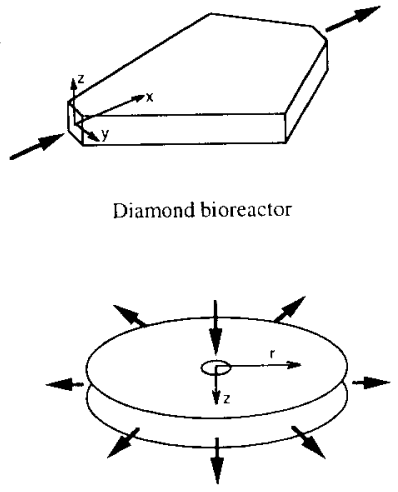

Radial bioreactor
Figure 3. (a) Four different parallel-plate Flow chambers and their coordinate systems.
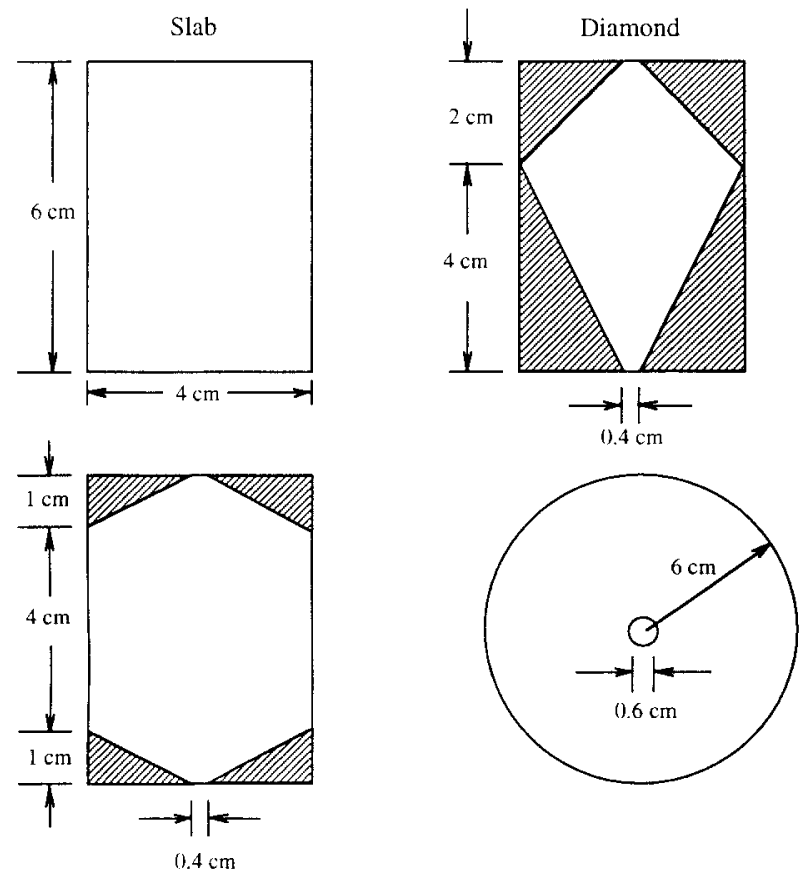

Gondola

Radial

Figure 3. (b) The detailed dimensions of the flow chambers of Figure 3 (a) seen through top-viewing. The configuration is essentially based on an aspect ratio of 3 to 2 (length $=6 \mathrm{~cm}$, width $=4 \mathrm{~cm}$ ). top-viewing, Figure $3 \mathrm{~b}$ provides the detailed dimensions of these four chambers. The configuration is essentially based on an aspect ratio of 3 to 2 (length $6 \mathrm{~cm}$, width $4 \mathrm{~cm}$ ). The slab chamber utilizing a manifold distributor to supply medium has a volume of $7.2 \mathrm{~cm}^{3}$; diamondand gondola-constructed chambers, based on the aspect ratio 1.5 , have volumes of $4.0 \mathrm{~cm}^{3}$ and $6.1 \mathrm{~cm}^{3}$, respectively. Fluid enters at the left end and exits from the right end of the three bioreactors (slab, diamond, and gondola). The radial-flow chamber with inner and outer radii $0.3 \mathrm{~cm}$ and $6 \mathrm{~cm}$ has a volume of $33.8 \mathrm{~cm}^{3}$. Fluid enters at the bottom of the hole and exits from the periphery. It should be noted that we tried basically to maintain the same axis length for these four bioreactors (i.e., $6 \mathrm{~cm}$ ). Therefore, the volumes of these four bioreactors are different. However, the residence time $V / Q$ (volume divided by flow rate) is maintained by changing the flow rate $Q$. Thus, the inlet velocities of these bioreactors are different (see Table I), while the Graetz number (defined below) is the same.

\section{Governing Equations}

The origin of the coordinate system (see Fig. 3a) chosen is at the center of the duct (for a radial-flow chamber, the origin is chosen at the bottom center). The cells are located on the bottom wall of the chambers. The application of appropriate symmetry conditions at the cross-sectional center line permits the restriction of the solution to the left half of the duct chambers. For the radial-flow chamber, we take one-quarter of the flow domain for the analysis (Fig. 3a).

The governing equations are the equation of continuity, the Navier-Stokes equation, and the convectivediffusion equation, depicted here in a vector format as

$$
\begin{aligned}
\boldsymbol{\nabla} \cdot \mathbf{u} & =\mathbf{0} \\
\boldsymbol{u}_{t}+\boldsymbol{u} \cdot \nabla \boldsymbol{u} & =-\frac{1}{\boldsymbol{\rho}} \nabla p+v \nabla^{2} \mathbf{u} \\
C_{t}+\boldsymbol{u} \cdot \nabla C & =D \nabla^{2} C
\end{aligned}
$$

The boundary conditions are:

$$
\begin{array}{lrlrl}
\text { At inlet: } & C=0 & \boldsymbol{u} & =u_{x} \\
\text { At bottom wall: } & D \frac{\partial C}{\partial n}=-\mathrm{K} & \boldsymbol{u} & =0 \\
\text { At top wall: } & D \frac{\partial C}{\partial n}=0 & \boldsymbol{u} & =0 \\
\text { At side wall: } & D \frac{\partial C}{\partial n}=0 & \boldsymbol{u} & =0 \\
& \text { At symmetry: } & D \frac{\partial C}{\partial n}=0 & u_{y}=u_{z}=0
\end{array}
$$

Equation (11) states that the medium flowing into the bioreactor does not contain the compound of interest 
Table I. Parameters of inlet velocity profile for different bioreactors.

\begin{tabular}{lrccc}
\hline & $a$ & $b$ & $c$ & $d$ \\
\hline Slab & $5.0 \times 10^{-5}$ & $-1.25 \times 10^{-5}$ & $-2.22 \times 10^{-3}$ & $5.56 \times 10^{-4}$ \\
Diamond & $2.75 \times 10^{-4}$ & $-6.88 \times 10^{-3}$ & $-1.22 \times 10^{-2}$ & 0.31 \\
Gondola & $4.25 \times 10^{-4}$ & $-1.06 \times 10^{-2}$ & $-1.88 \times 10^{-2}$ & 0.47 \\
\hline
\end{tabular}

The inlet flow velocity profile is assigned as the shape of parabola. The mathematical formula used is $u_{x}=a+b y^{2}+c z^{2}+d y^{2} z^{2}$ ( $u_{y}=u_{z}=0$ in the inlet). The parameters $a$, $b, c$, and $d$ are calculated based on $\mathrm{Gz}$ of unity.

and the only velocity component is $u_{x}$. Equation (12) represents the mass flux of the secreted growth factor from the feeder layer located on the bottom wall. No slip fluid is assumed at the bottom wall. Equations (13) and (14) state that the top wall and left side wall are impervious to cytokines and no slip boundary condition. Equation (15) gives the symmetry condition at the crosssectional center lines. Finally, at the outflow boundary where the fluid leaves the calculation domain, neither the value nor the flux of concentration is known. This outflow boundary condition is considered as a free boundary condition. ${ }^{12,42}$ The boundary conditions mentioned above are for slab, diamond, and gondola configurations.

For the radial-flow reactor, Equations (12) and (13) remain the same, but Equations (11) and (14) are changed to

$$
\begin{aligned}
& \text { At inlet: } \quad C=0 \quad \boldsymbol{u}=u_{z} \\
& \text { At cyclic plane: } \quad D \frac{\partial C}{\partial n}=0 \quad u_{n}=0
\end{aligned}
$$

Equation (17) describes the symmetry condition for concentration and the normal velocity is zero for two cyclic planes. Equation (15) is not necessary for this configuration.

\section{Assumptions}

Standard assumptions are used here. The flow is assumed to be fully developed, steady, and laminar with constant fluid properties. For the velocity profile to be fully developed, the entrance length for the flow must be small compared to the total length of the bioreactor, where the entrance length $L_{e}$ was estimated as ${ }^{28}$

$$
L_{e} \cong 0.05 \cdot H \cdot \operatorname{Re}
$$

For our maximum Reynolds number of $10^{-3}$ and $H=$ $0.3 \mathrm{~cm}$, the entrance length was negligible (the length of the bioreactor used is $6 \mathrm{~cm}$ ).

\section{Dimensional Analysis and Formulation of Key Dimensionless Groups}

There are two relative property ratios that are of key concern. One deals with the distribution of the secreted protein over the flow domain, while the second measures the importance of the local growth factor concentration.

The first one is the Graetz $(\mathrm{Gz})$ number. It is defined as the ratio of diffusional time $\left(H^{2} / D\right)$ to transit time $(V / Q) \cdot$

$$
\mathrm{Gz}=\frac{H^{2} / D}{V / Q}=\frac{\text { diffusional time }}{\text { transit time }}
$$

It measures the relative time of lateral diffusion to the convective transit time through the perfusion chamber. If the Graetz number is small, diffusional time is slow, relative to the transit time, and the local growth factor concentration can build up over time. Conversely, when the Graetz number is larger, the secreted factor is efficiently swept out by the fluid flow and the local growth factor concentrations are lowered. At a Graetz number of unity, the two processes are approximately in balance. Knowing $\mathrm{Gz}, H, D$, and, $V$ one can calculate volume flow rates $(Q)$ for a desired Graetz number and the corresponding entrance velocities for the four bioreactors.

The local growth factor concentration determines the strength of the mitogenic stimulus. The appropriate reference scale for the local growth factor concentration $\left(C_{o}\right)$ can be obtained by making the growth factor secretion boundary condition dimensionless. By introducing dimensionless concentration and depth variables, $C=$ $C_{o} \theta$ and $n=H \zeta$, into Equation (12), we obtain

$$
\frac{D C_{0}}{H K} \frac{\partial \theta}{\partial \zeta}=-1
$$

Let $\left(D C_{0}\right) /(H K)=1$; thus the concentration reference scale is defined as

$$
C_{0}=\frac{H K}{D}=\frac{H^{2}}{D} \cdot \frac{K}{H}
$$

where $H$ represents the depth of the chambers. The reference concentration is a product of the volumetric growth factor secretion rate $(K / H)$ and the diffusional response time $\left(H^{2} / D\right)$. The second key dimensionless number is then

$$
\mathrm{P}=K_{s} / C_{o}=K_{s} \mathrm{D} / \mathrm{HK}
$$

which represents the interplay of the growth factor production $(K / H)$, diffusion $\left(H^{2} / D\right)$, and stimulation $\left(K_{S}\right)$. 


\section{Numerical Values}

The diffusion coefficients for secreted protein can be estimated from the Stokes-Einstein equation or obtained from published data on protein diffusion. ${ }^{70}$ They are in the range of $D \cong 5 \times 10^{-7}$ to $10 \times 10^{-7} \mathrm{~cm}^{2} / \mathrm{s}$ (we used $5 \times 10^{-7} \mathrm{~cm}^{2} / \mathrm{s}$ for this study). The fluid properties $\left(v=0.007 \mathrm{~cm}^{2} / \mathrm{s}, \rho=1.0 \mathrm{~g} / \mathrm{cm}^{3}\right)$ used are typical of those for growth medium at $37^{\circ} \mathrm{C}$. The inlet flow velocity was calculated for a given Graetz number and described by a parabolic distribution. For example at Gz of unity, inlet velocity is formulated as $u_{z}=9.97 \times 10^{-4}-1.11 \times$ $10^{-2} \mathrm{r}^{2}$ centimeters per second for radial flow chamber; but for the remaining three configurations it is $u_{x}=a$ $+b y^{2}+c z^{2}+d y^{2} z^{2}$ centimeters per second, where the parameters $a, b, c$, and $d$ are listed in Table I for each geometry. Here, we take the slab geometry as an example to illustrate the approach of inlet parabola velocity profile. First,

$Q=G z \cdot V \cdot D / H^{2}=\frac{1 \times 7.2 \mathrm{~cm}^{3} \times 5 \cdot 10^{-7} \mathrm{~cm}^{2} / \mathrm{s}}{\left(\begin{array}{c}0.3 \mathrm{~cm})^{2} \\ =4 \times 10^{-5} \mathrm{~cm}^{3} / \mathrm{s}\end{array}\right.}$

The maximal inlet velocity is then equal to

$1.5 \cdot \bar{u}=1.5 \cdot Q /($ inlet cross section area $)$

$$
=\frac{1.5 \times 4 \cdot 10^{-5} \mathrm{~cm}^{3} / \mathrm{s}}{4 \mathrm{~cm} \times 0.3 \mathrm{~cm}}=5 \cdot 10^{-5} \mathrm{~cm} / \mathrm{sec} .
$$

Then, the inlet parabola velocity can be expressed as

$$
\begin{gathered}
u=5 \times 10^{-5}-\frac{5 \times 10^{-5}}{2^{2}} y^{2} \\
-\frac{5 \times 10^{-5}}{0.15^{2}} z^{2}+\frac{5 \times 10^{-5}}{2^{2} \times 0.15^{2}} y^{2} z^{2} \quad \mathrm{~cm} / \mathrm{s}
\end{gathered}
$$

where $2 \mathrm{~cm}$ and $0.15 \mathrm{~cm}$ are the half of the width and depth of the inlet square hole.

The numerical value of $P$ can be estimated. Based on a growth factor production rate of $50-5000$ molecules/ cell/s (5000 is in the middle range of $2000-8000$ and 50 is $1 \%$ of that) and cell density $10^{5}$ cells $/ \mathrm{cm}^{2}$, the range of numerical values for $K$ is 0.01 to $1 \mathrm{p} M \cdot(\mathrm{cm} / \mathrm{s})$. Given $H=0.3 \mathrm{~cm}$ and $D=5 \times 10^{-7} \mathrm{~cm}^{2} / \mathrm{s}$, we can estimate the reference concentration to be $(H K) / D=6$, . . , 600 nM. With $K_{s}$ values in the range of 0.05 to $5.0 \mathrm{ng} / \mathrm{mL}$, the expected numerical values of $P$ fall in the range of $5 \times 10^{-6}-0.1$ for growth factors such as epidermal growth factor (EGF; $\mathrm{MW}=6 \mathrm{kDa}^{1}$ ) and granulocyte colony-stimulating factor (G-CSF; MW = $\left.19.6 \mathrm{kDa}^{1}\right)$.

\section{Numerical Methods}

\section{Algorithm}

A finite element method program FIDAP ${ }^{12}$ (FDI, version 7.02) was used to obtain the numerical solutions.

This method transforms the governing equations into a system of nonlinear ordinary differential equations. To solve the nonlinear system of matrix equations, a segregated solution algorithm in FIDAP was selected which solves sequentially and separately for each active degree of freedom (i.e., velocity, pressure, and concentration). This method requires less disk storage compared to other solution algorithms available in FIDAP. When solving the equations, the maximum iterative number was set to 60 and the convergence tolerance for all freedoms was set to 0.001. A HP9000-730 workstation was used for these computations. The unilineage model system was readily solved using any standard numerical method that integrates a set of ordinary differential equations. For the computations presented here, the Runge-Kutta fourth-order method ${ }^{6}$ was used to integrate the differential equations.

\section{Mesh Generation}

The flow domain of each bioreactor (half part due to symmetry) was discretized into a large number of isoparametric brick elements (shown as Fig. 4) with eight nodes by the preprocessor FI-GEN (Fluid Dynamics International Inc., Evanston, IL). The mesh was graded finely close to the side and bottom walls, where the most significant changes in the concentration occur. The numbers of nodes and elements utilized are listed in Table II. In each element the concentration field was approximated by a function

$$
C=\sum_{j=1}^{n} \phi_{j} C_{j}
$$

where $\phi_{j}$ is the trilinear basis function. Mesh optimization was achieved by testing the influence of mesh density on the concentration distribution on the bottom wall. The convergence of the numerical solution was verified by mesh refinement. Finally, Matlab ${ }^{31}$ (Mathworks Inc., Natick, MA) was used for generating meshed surface plots of growth factor concentrations and cell densities.

\section{Measurement of Nonuniformity}

The overall nonuniformity can be estimated by the coefficient of variance. The coefficient of variance $(\lambda)$ is defined as the ratio of the standard deviation $(\sigma)$ to the mean $(\bar{C})$. The smaller is the coefficient of variance, the more uniform is the microenvironment provided by the bioreactor.

When considering the two-dimensional growth area, the standard deviation and mean are defined as

$$
\sigma^{2}=\frac{\int(C-\bar{C})^{2} d x d y}{\int d x d y} \quad \bar{C}=\frac{\int C d x d y}{\int d x d y}
$$

It should be noted the value of $\sigma^{2}$ and $\bar{C}$ are normalized 

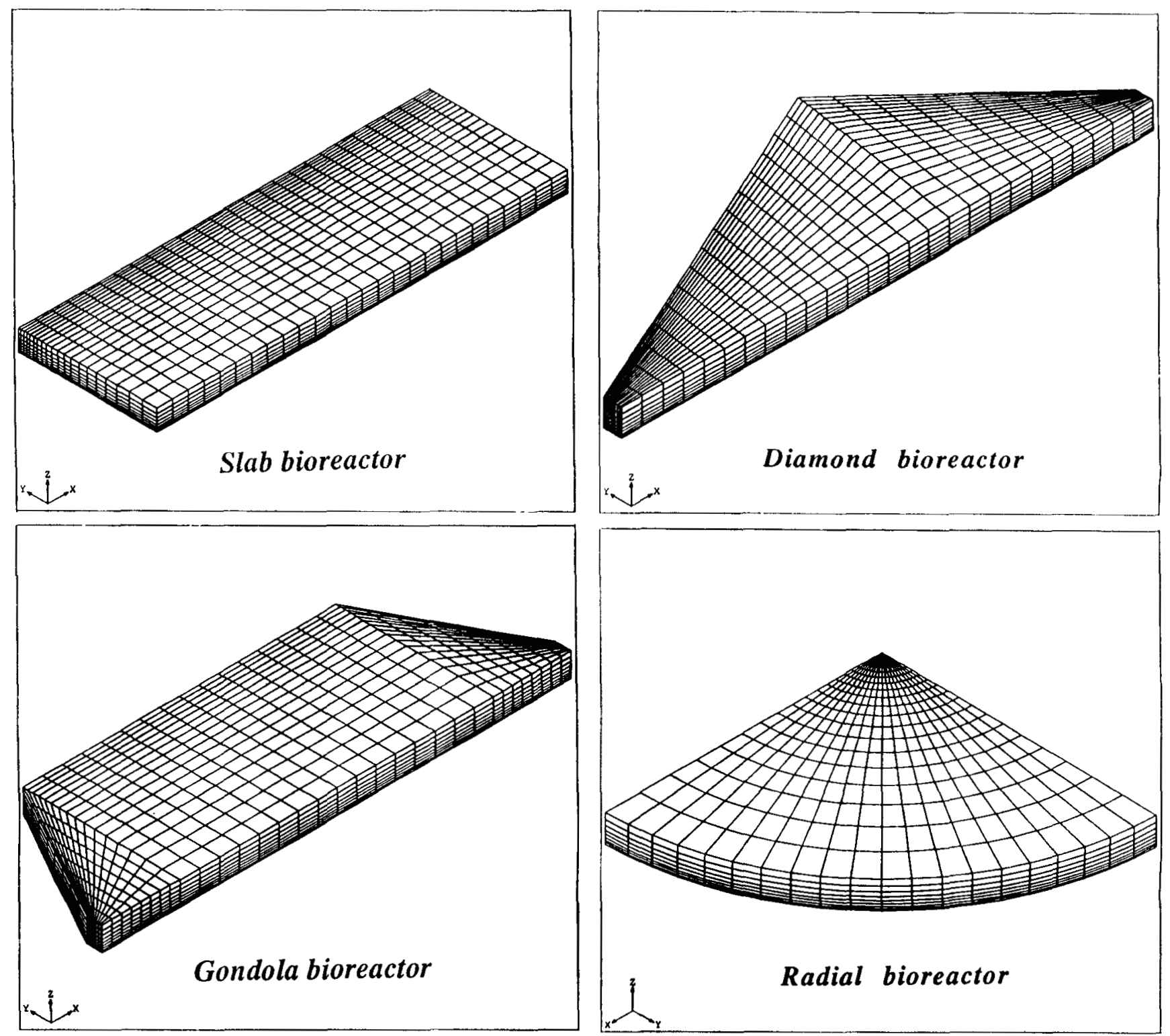

Figure 4. Mesh-generated computational domains of the four bioreactor geometries.

with the surface area (i.e., $\int d x d y$ ). Thus, they are independent of the surface area of bioreactors.

\section{RESULTS}

\section{Motivating Experimental Observation}

We have consistently observed that bone marrow cultures carried out in parallel-plate bioreactors display a nonuniformity in growth close to side walls that are oriented parallel to the flow direction. Figure 5 shows how a higher cell density appears near the side walls of a diamond-shaped bioreactor after 7 days of cell culture. How is the pattern formed and what possible mechanism leads to its formation? Three possible mechanisms are (i) accelerated cell growth due to stroma-secreted growth factors that concentrate in the slower flowing regions near the side wall; (ii) directed cell migration induced by chemotaxis caused by buildup of chemoattractants near the side wall; and (iii) cell drift due to hydrodynamic shear stress. Since an insignificant fraction of the cells were detected in the effluent, we can conclude the hydrodynamic force is not stronger than the adhesive force to detach the hematopoietic cells away from the bottom surface. This conclusion is readily supported by order-of-magnitude calculations..$^{43}$ In this study, we explore numerically the consequences of differential growth driven by stroma-derived cytokines.

\section{How Key Dimensionless Property Ratios Influence Concentration of Growth Factor on Cell Bed}

The computed concentration profiles for the secreted growth factor show that the local concentrations at the 
Table II. Numbers of nodes and elements utilized for four bioreactors.

\begin{tabular}{lccccc}
\hline & $\begin{array}{c}\text { Nodal points } \\
\text { in } \mathbf{x} \text {-direction }\end{array}$ & $\begin{array}{c}\text { Nodal points } \\
\text { in y-direction }\end{array}$ & $\begin{array}{c}\text { Nodal points } \\
\text { in z-direction }\end{array}$ & Total nodes & $\begin{array}{c}\text { Total } \\
\text { elements }\end{array}$ \\
\hline Slab & 27 & 21 & 9 & 5103 & 4160 \\
Diamond & 27 & 19 & 9 & 4617 & 3744 \\
Gondola & 33 & 17 & 9 & 5049 & 4096 \\
Radial & & & & & \\
$\quad \begin{array}{l}\text { Inlet region } \\
\text { Radial region }\end{array}$ & 11 & 11 & 9 & 3969 & 3360 \\
\hline
\end{tabular}
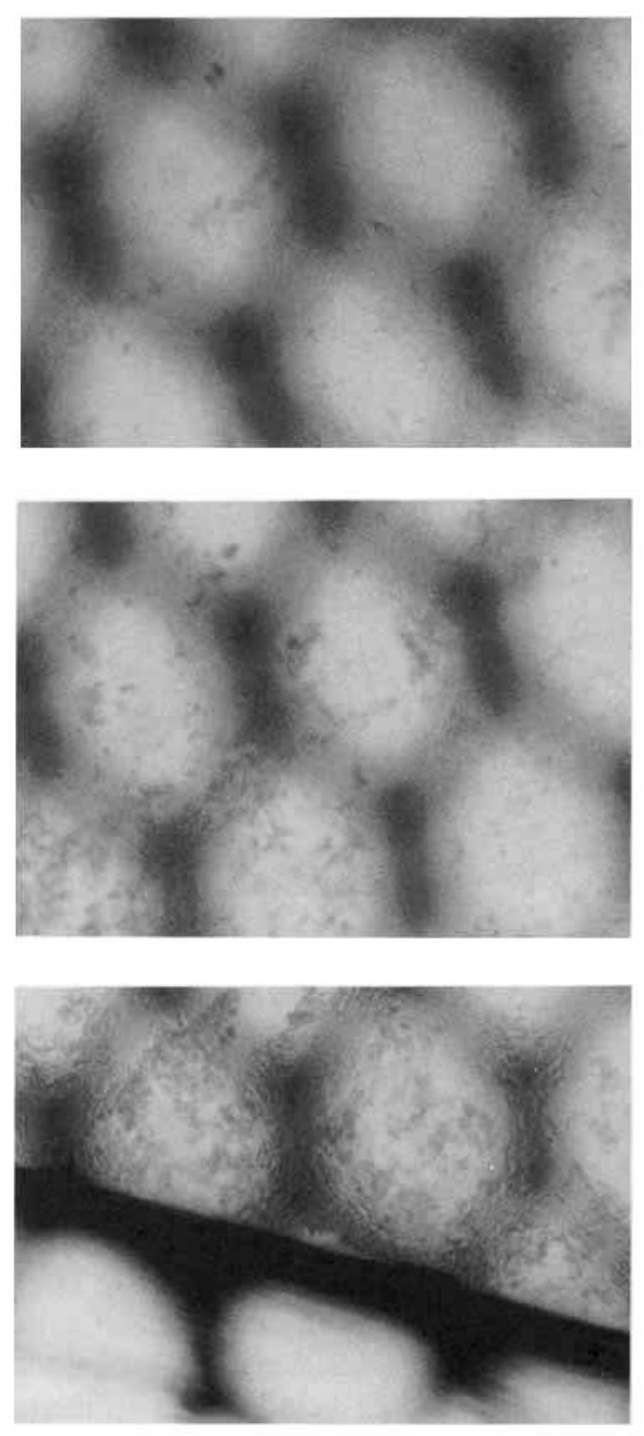

Figure 5. Photomicrographs of bone marrow cell distributions (day 7) on the bottom of the diamond-shaped perfusion bioreactor. The pictures from top to bottom indicate the area from near the center bottom of the bioreactor to close to the side wall of the bioreactor. These demonstrate that cell density is higher near the bottom side wall. The hexagonal-shaped background is a shadow from a support mesh in the membrane used to separate the gas and liquid phases within the bioreactor. This bioreactor was operated under the condition of $\mathrm{Gz}=1.0$. growth surface are unevenly distributed (Fig. 6). The high growth factor concentrations formed near the side wall are due to the slower fluid flow in this region that results from the no-slip condition caused by the side wall. Therefore, local nonuniformities in the concentration of the growth factor at the bottom of three of the four bioreactor geometries considered are very prominent near the side wall. Conversely, the radial geometry which has no internal side wall does not exhibit this behavior. All four geometries do exhibit axial concentration gradients, which are influenced by the Graetz number.

The concentration gradients in the $x$ and $y$ directions are shown in more detail in Figure 7 at various Graetz numbers (using $0.1,1$, and 10 ). Figure 7 a presents the spanwise concentration gradient at halfway of downstream (i.e., at $x=3 \mathrm{~cm}$ ). The concentration profile extending from the side wall varies with the Graetz number. The concentration of secreted cytokine at the cell bed under slow flow $(\mathrm{Gz}=0.1)$ is higher than under fast flow $(\mathrm{Gz}=10.0)$. The uniformity of the concentration profile is increased as the flow rate is increased.
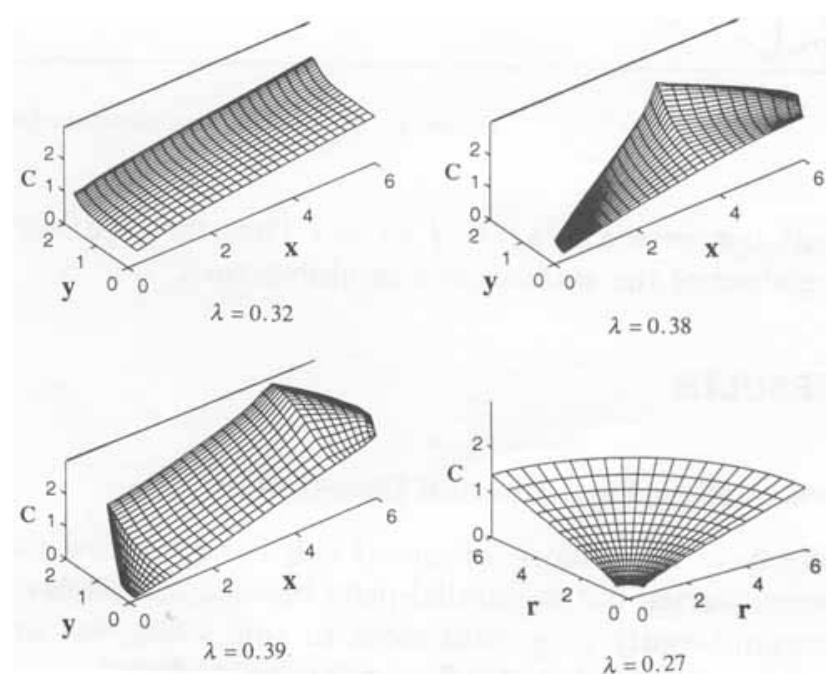

Figure 6. Concentration profiles on the bottom surface and corresponding $\lambda$ of four different bioreactor geometries with $\mathrm{Gz}=1.0$. Given $H=0.3 \mathrm{~cm}, D=5 \times 10^{-7} \mathrm{~cm}^{2} / \mathrm{s}$, and $K=0.1 \mathrm{p} M \cdot(\mathrm{cm} / \mathrm{s})$, the reference concentration $(H K / D)$ is $60 \mathrm{n} M$. The dimensionless concentration can be converted into a dimensional unit through the reference concentration. 

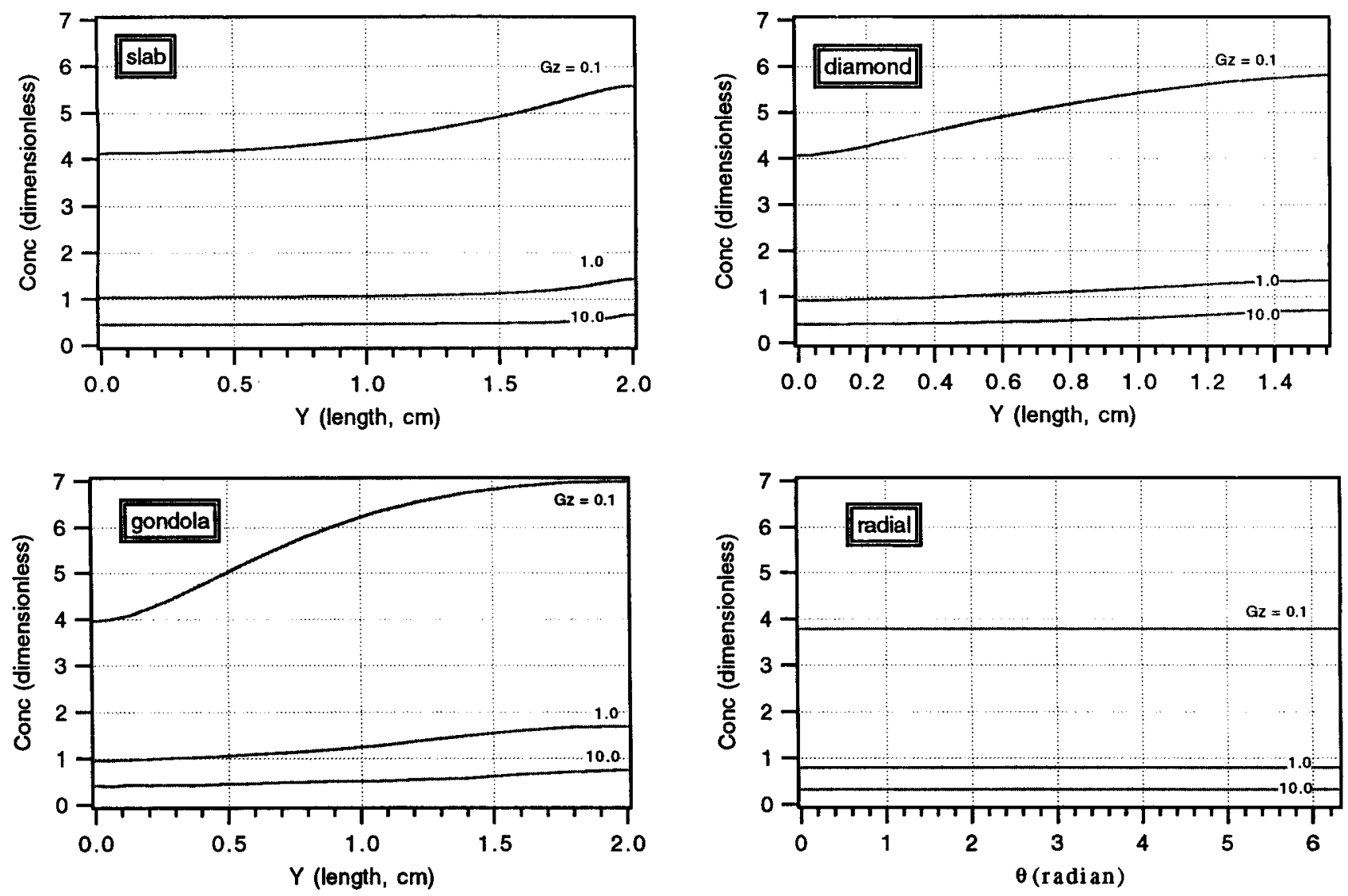

(a)
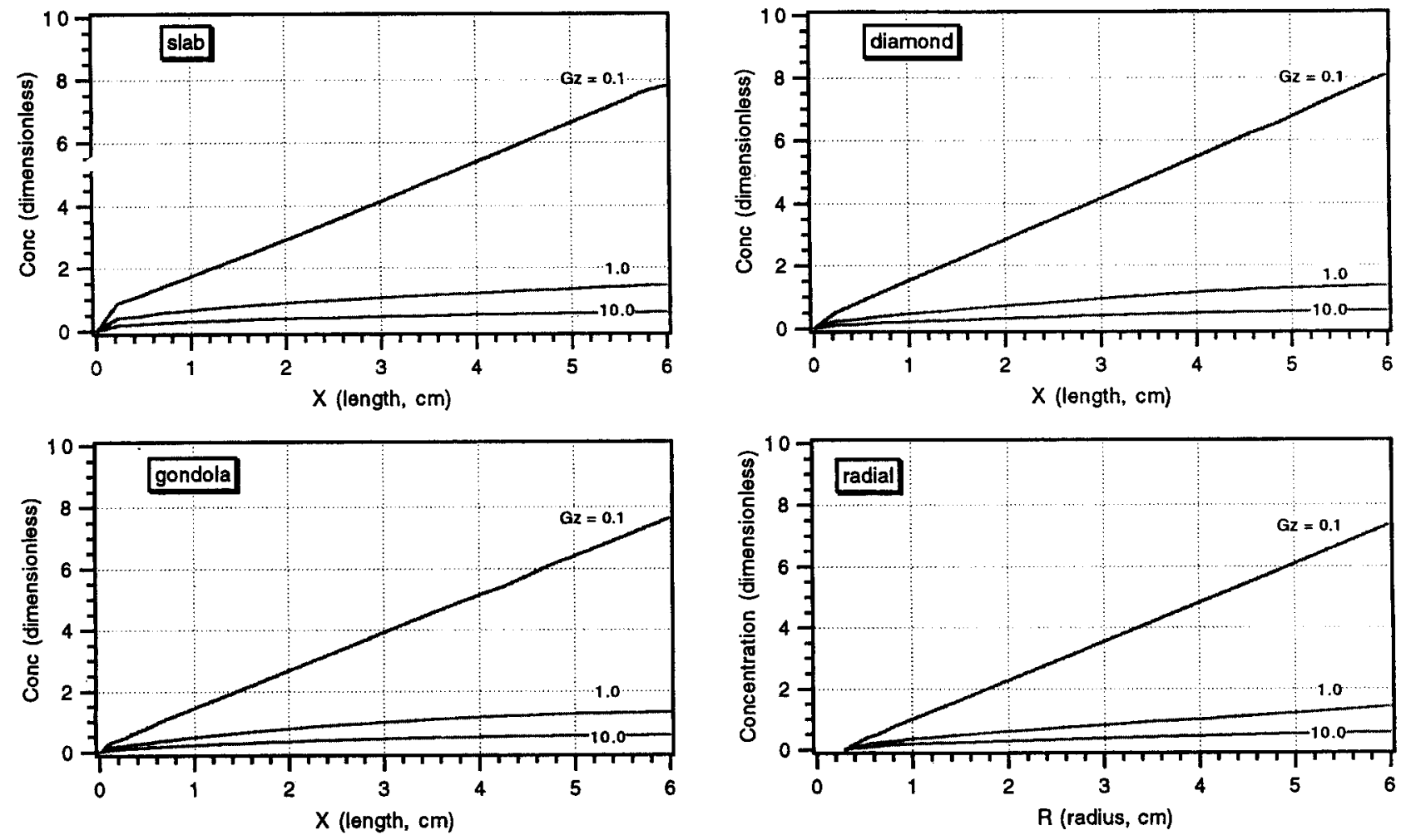

(b)

Figure 7. Representative concentration profiles of four bioreactors under $\mathrm{Gz}=0.1,1.0$, and 10.0: (a) spanwise concentration distribution at halfway of downstream; (b) axial concentration distribution at the bottom line of symmetrical plane. As in Figure 6, the dimensionless concentration can be converted into a dimensional unit through the reference concentration. 
Again, the radial-type bioreactor gives the most uniform concentration distribution due to no internal side walls. Figure $7 \mathrm{~b}$ shows the axial concentration profiles at the bottom line of the symmetrical plane for four different bioreactors which have nearly the same concentration gradients under different $\mathrm{Gz}$ numbers.

The concentration gradients were a function of bioreactor geometry and the Graetz number. The concentration gradients in the flow direction are influenced by the $\mathrm{Gz}$ number. The concentration gradients perpendicular to the flow are significant except for the radial geometry. The local concentrations in turn influence the cell growth and differentiation rates, and this influence is modulated by the $P$ number.

\section{How Dimensionless Property Ratios Influence Growth Pattern}

The uneven distribution of the growth factor will induce nonuniform cell growth (Fig. 8). As with the local concentrations of the growth factor, the overall cell density varies both in the $x$ and $y$ directions. Again cell growth in the radial geometry exhibits the most uniform pattern due to the absence of the side wall effect on the concentration distribution.

The nonuniform growth will be influenced by both of the dimensionless property ratios. The spatiotemporal patterns of overall cell densities (the total cell number in the four compartments in Fig. 2) for the four bioreactors were computed for various values of $P\left(=K_{S} / C_{o}\right)$ for the three Graetz numbers used above to determine the concentration distributions. The coefficient of variance varies strongly with the governing dimensionless groups (Fig. 9).

The coefficient of variance is small for small values of $P$. Under these conditions the variation in growth
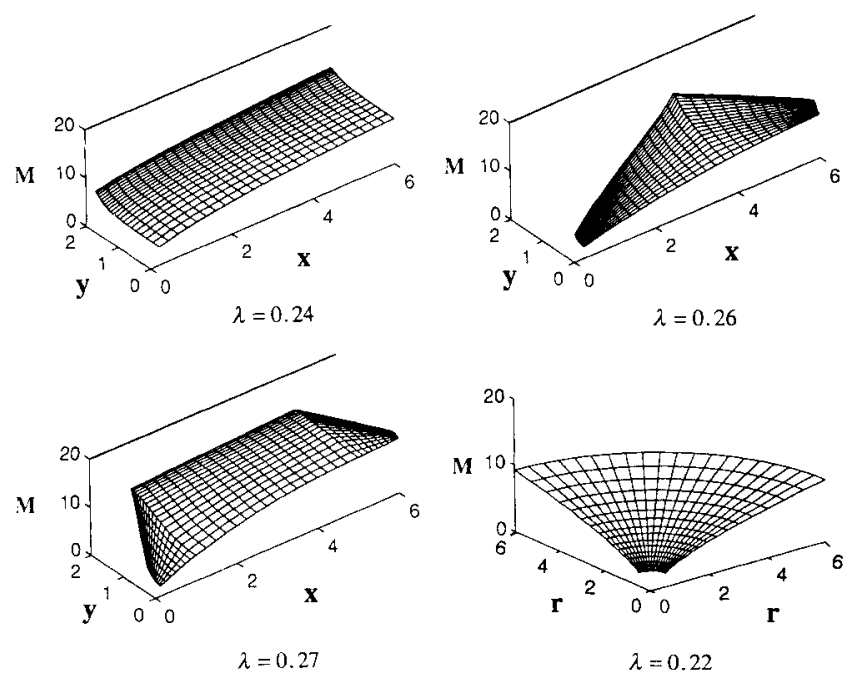

Figure 8. Distributions of cell density on the bottom and corresponding $\lambda$ of four bioreactors operated at $\tau=5.0$, with $P=1.0$ and $\mathrm{Gz}=1.0$.
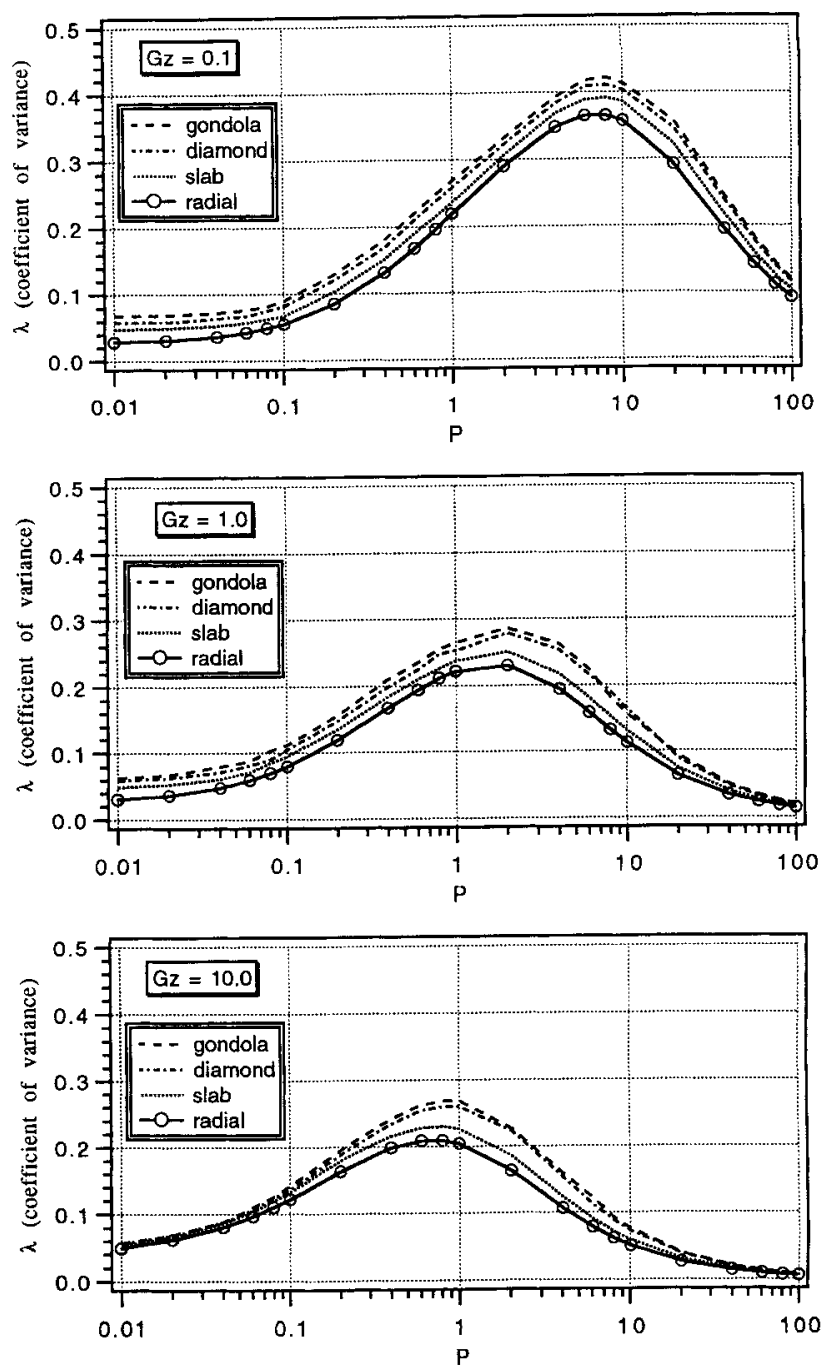

Figure 9. Coefficient of variance for the distributions of cell density in the four different bioreactor geometries as functions of $P$ for three Gz numbers.

factor concentration is not important since even the lower concentrations will exceed $K_{S}$ and growth proceeds at a maximal rate throughout the entire cell bed. The coefficient of variance increases as $P$ approaches unity. There the local concentration of the growth factor is close to the $K_{S}$ value, and variations around this condition will lead to significant differences in growth rates. As $P$ increased above unity, the coefficient of variation decreases again since the growth factor concentration is lower than $K_{S}$ and little growth is observed through the entire cell growth surface. Although the coefficient of variance is similar for all reactor geometries, the radial-flow bioreactor generates the relatively uniform cell distribution among these four bioreactors.

The average cell density $(\bar{M})$ is given as Figure 10 . Under the same conditions ( $\mathrm{Gz}$ and $P$ ), the four geometries generate almost identical average cell density. The cell densities under low-Gz-number conditions are higher than they are under high-Gz-number conditions. 


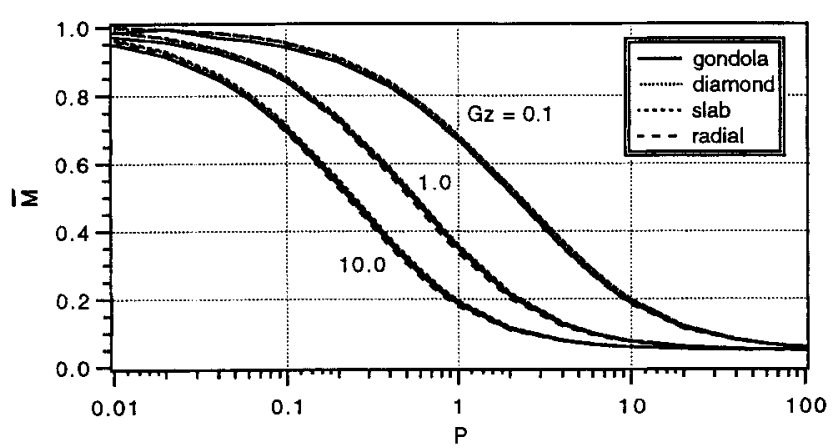

Figure 10. Average cell density on the bottom of four bioreactor geometries as functions of $P$ for three Gz numbers.

The reason is that, at a low $\mathrm{Gz}$ number (i.e., less than unity), the growth factor secreted from the feeder layer (i.e., stromal cells) diffuses faster than the convective flow can carry it away. Therefore the growth factor can accumulate more near the cell bed than it can under the conditions of a $\mathrm{Gz}$ number greater than unity. Figure 9 reveals that, for $P$ less than unity, the nonuniformity of cell distribution slightly increases with increasing $\mathrm{Gz}$ number. While, for $P$ greater than unity, the nonuniformity of cell distribution decreases with increasing $\mathrm{Gz}$ number.

Finally, a quantitative parameter plan diagram was generated to depict the effects of the two parameters $\mathrm{Gz}$ and $P$ on cell growth and distribution within bioreactors (Fig. 11). In this figure, the uniformity of cell distribution
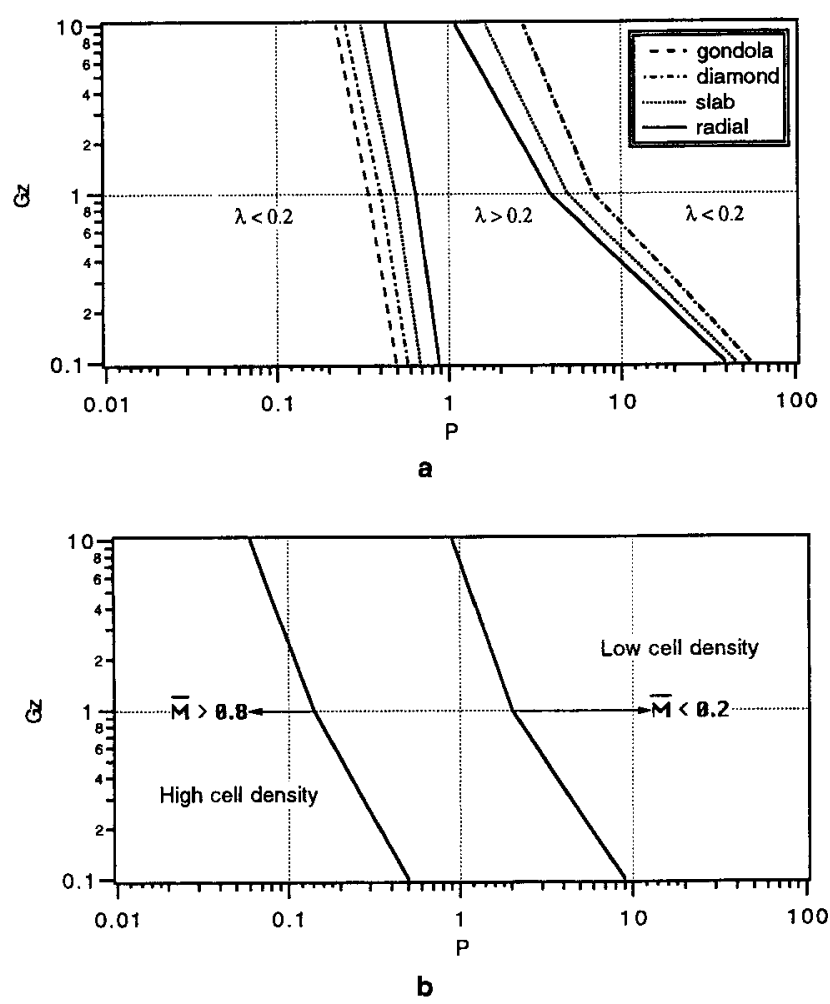

Figure 11. Parameter plane illustrating the effects of $\mathrm{Gz}$ and $P$ on (a) the uniformity of cell distribution and (b) average cell density within four bioreactor geometries. is defined as $\lambda<0.2$; the high average cell density is defined as $\bar{M}>0.8$ and low cell density as $\bar{M}<0.2$. The radial-flow bioreactor provides more uniform cell distribution within a wide range of $\mathrm{Gz}$ and $P$.

\section{DISCUSSION AND CONCLUSION}

The function of living tissue involves an intricate interplay between physicochemical and biological rate processes. The balance between these simultaneously occurring processes needs to be restored in ex vivo systems in order to obtain accurate simulation of tissue function. This requirement applies to bioreactors that are designed to reconstitute physiologic structure-function relationships accurately so that scientific studies are enabled and production of clinical doses of cells for cellular therapies realized.

Parallel-plate bioreactors of various geometries have been employed for these purposes. ${ }^{16,20,21,41,50}$ We show here that previously published two-dimensional analyses of parallel-plate configurations are insufficient to describe cultures that have important trafficking of internally produced protein, such as growth factors and chemo-attractants, that affect cellular replication and differentiation. The present study is focused on the concentration distribution of stromally secreted growth factor in four different geometries of parallel-plate bioreactors close to such side walls. The computational results (Fig. 6) show that a peak concentration for all bioreactor geometries (except radial shape) occurs in the bottom corners. Here the low medium-flow velocities provide for a lower rate of removal than at the center of the bioreactor where flow velocities are high. This flowinduced concentration difference leads to a diffusion process and an accompanying concentration boundary layer. Two key dimensionless quantities were found to govern the extent and uniformity of growth of a bed of parenchymal cells that develop on a growth factor secreting stromal layer.

For steady flow at low Reynolds number in a slab bioreactor, velocity gradients exist near the side walls. These Hele-Shaw flows have a hydrodynamic boundary layer thickness near the side walls that is approximately the same as the depth of the bioreactor. In sharp contrast, the thickness of the concentration boundary layer can be several-fold larger than the depth of the bioreactor. ${ }^{44}$ For the other two bioreactor geometries (diamond and gondola) that have one inlet and one outlet port, the existence of side walls and cross-sectional shape varying with longitudinal distance ( $x$ direction) makes the coefficient of variance for the concentration slightly larger than the value computed from slab geometry. Numerical results for the concentration distributions immediately over the cell bed in the different geometries (see Fig. 6) indicate that the radial-flow chamber has relatively more uniform concentration distributions than other configurations due to the absence of an inter- 
nal side wall effect. In addition, due to axisymmetry, the radial-flow bioreactor can be analyzed as a twodimensional problem which saves computational time.

A unilineage model describing growth and differentiation was formulated. This model used a Monod-type kinetics for the stromally derived growth-stimulatory factor. The unilineage model combined with the convective-diffusion description of the secreted growth factor predicts that a spatiotemporal cell growth pattern develops in parallel-plate bioreactors (Fig. 8). The uneven growth pattern is less prominent as the key dimensionless quantity $P\left(=K_{S} / C_{o}\right)$ is much smaller than unity. This uniformity in cell growth results from the fact that the growth rates are relatively insensitive to the concentration of the stromally derived factor. Uniformity in cell growth also was exhibited for large $P$ (much greater than unity) since growth rates are low and few cells are produced. The nonuniformity in cellular growth rates is most prominent for values of $P$ in the range of 0.1 to 10 (see Fig. 9). Within this range, the specific growth rates vary strongly with distance from the side wall. Thus, the dimensionless parameter $P$ is a critical factor for determining the uniformity of the spatiotemporal development of tissues. From available literature, ${ }^{15,27,32}$ we estimated that the $P$ values of endogenous growth factors are likely to be in the range of 0.01 to 1 and possibly much lower than 0.01 .

The Gz number controls the cell density in the bioreactor. Figure 10 shows that the higher cell density can be obtained at a low $\mathrm{Gz}$ number as compared to high $\mathrm{Gz}$ numbers. This difference is due to the fact that a low $\mathrm{Gz}$ numbers the growth factor secreted from the stromal layer diffuses faster than the convective flow can carry it away. Therefore the growth factor can accumulate into higher local concentrations near the cell bed than it can at high $\mathrm{Gz}$ numbers.

The $\mathrm{Gz}$ number calculated above is based on endogenously produced growth factors. Since the diffusion coefficient for small molecules, such as glucose and amino acids, is at least 10 times greater than that for proteins, the $\mathrm{Gz}$ for small molecules is correspondingly smaller. Therefore, sufficient nutrients supplied from the medium can be delivered to the cell bed before being washed out from the bioreactor. Similarly, under the same flow rate, the metabolic by-products (e.g., lactate) secreted from stroma cells can be carried away from the cell bed about 10 times faster than the secreted endogenous growth factors because the diffusion coefficient of lactate is 10 times higher than that of the growth factors. Thus, there should be little concern about nutrient limitation or waste accumulation even under conditions where uneven concentrations exists for endogenously produced growth factors.

There exists another potentially important consequence of an uneven distribution of stromally derived protein. Directed parenchymal cell motion can be induced by the concentration gradient of a stromally derived chemo-attractant. This phenomenon of concentration-gradient-driven cell motion is due to the well-known process of chemotaxis. ${ }^{67}$ Several cell types show the ability to move toward a high concentration of chemo-attractants. Some reports ${ }^{30,69}$ have suggested that hematopoietic stem cells have the capability of being induced to migrate by this process. Is the concentration gradient near the side walls on the cell bed high enough to drive cells to migrate toward the walls? The estimation of the magnitude of the concentration gradient emanating from the side wall suggests that the answer is yes. ${ }^{44}$

Thus the consequences of uneven concentration distributions of stromally derived protein are twofold: uneven localized growth or directed motion of cells to particular locations. Of course both of these processes can occur simultaneously and can lead to nonuniform cell growth. In order to distinguish between these processes, an experimental study employing time lapse videography and image analysis would be required.

The present analysis represents a simplified case of a complex process. Although the results are conceptually useful, particularly in terms of the dimensionless groups identified and their subsequent value in orderof-magnitude estimations, there are several underlying assumptions in the current analysis of which one needs to be cognizant. The growing cell bed creates a "granular" characteristic of the surface. From a hydrodynamic standpoint this characteristic may influence the exact applicability of the no-slip boundary conditions. Although the present model may not accurately account for this possible effect, such alterations are not expected to change the major conclusions reached herein. The biology considered and modeled may not account for all the complexities that occur in some biological systems. For instance, secreted protein may bind to extracellular matrix molecules. Further, high consumption rates of the secreted factors by the parenchymal cells will affect the concentration distributions. Such additional effects can readily be accounted for in the type of model developed here. Once known and characterized experimentally, these processes can be incorporated and their effects on overall bioreactor performance assessed.

In summary, the focus of this study was to characterize the interplay between physicochemical dynamics and biological rate processes that take place in parallel-plate bioreactors that are used to grow complex tissue cultures. Specifically, the effects of stromally derived protein on growth and differentiation of parenchymal cells were analyzed. The interplay of the participating dynamics are very complicated and require an integrated model. The results show that for the biological situation considered, significant differences in the concentration endogenously secreted growth factors can occur near 
side walls. This nonuniformity in turn can affect the growth and differentiation of parenchymal cells. The extent of heterogeneity in cellular growth is described by two dimensionless numbers: the well-known Graetz number and a new dimensionless quantity, called $P$. The effects caused by side walls can be eliminated by using a radial configuration.

This work was supported by a grant from Aastrom Biosciences Inc., Ann Arbor, Michigan, and grant No. NAG9-652 from NASA.

\section{NOMENCLATURE}

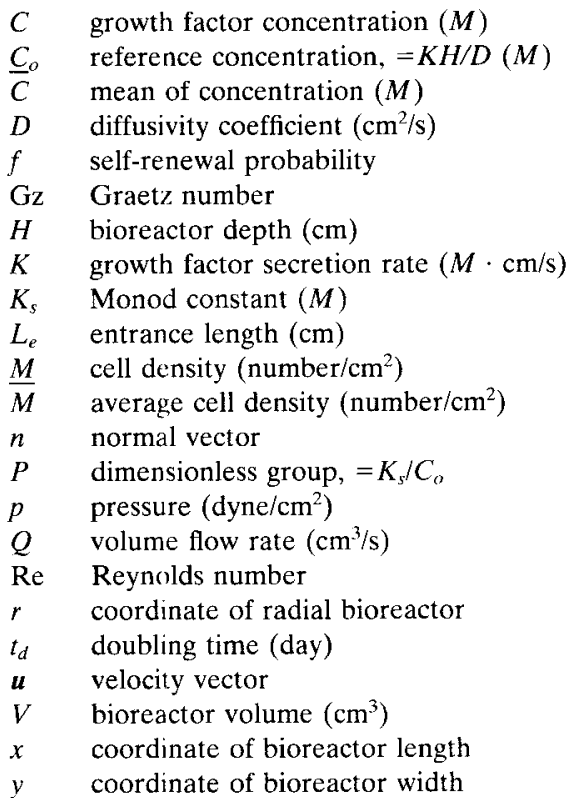

\section{Greek Letters}

$\begin{array}{ll}z & \text { coordinate of bioreactor height } \\ \phi & \text { trilinear basis function } \\ \lambda & \text { coefficient of variance } \\ \mu & \text { cell growth rate }\left(\mathrm{day}^{-1}\right) \\ \mu_{\max } & \text { maximal growth rate }\left(\mathrm{day}^{-1}\right) \\ \nu & \text { kinematic viscosity }\left(\mathrm{cm}^{2} / \mathrm{s}\right) \\ \theta & \text { dimensionless concentration } \\ \rho & \text { density of medium }\left(\mathrm{g} / \mathrm{cm}^{3}\right) \\ \sigma & \text { standard deviation } \\ \tau & \text { dimensionless time }\end{array}$

\section{References}

1. Aggarwal, B. B., Gutterman, J. U. (eds.). 1992. Human cytokines. Blackwell Scientific Publications, Boston.

2. Asonuma, K., Vacanti, J. P. 1992. Cell transplantation as replacement therapy for the future. Critical Care Nurs. Clin. N. Am. 4: $249-254$

3. Berardi, A. C., Wang, A., Levine, J. D., Lopez, P., Scadden, D. T. 1995. Functional isolation and characterization of human hematopoietic stem cells. Science 267: 104-108.

4. Berthiaume, F., Toner, M., Tompkins, R. G., Yarmush, M. L. 1994. Tissue engineering. pp. 363-386. In: R. S. Greco (ed.), Implantation biology: The host response and biomedical devices. CRC Press. Boca Raton, FL.
5. Caplan, A. I. 1991. Mesenchymal stem cells. J. Orthop. Res. 9: 641-650.

6. Carnahan, B., Luther, H. A., Wilkes, J. O. 1969. Applied numerical methods. Wiely, New York.

7. Cozens-Roberts, C., Quinn, J. A., Lauffenburger, D. A. 1990. Receptor-mediated adhesion phenomena: Model studies with the radial-flow detachment assay. Biophys. J. 58: 107-125.

8. Cronkite, E. P. 1988. Analytical review of structure and regulation of hemopoiesis. Blood Cells 14: 313-328.

9. Crouch, C. F., Fowler, H. W., Spier, R. E. 1985. The adhesion of animal cells to surfaces: The measurement of critical surface shear stress permitting attachment or causing detachment. J. Chem. Tech. Biotechnol. 35B: 273-281.

10. Davis, A. A., Temple, S. 1994. A self-renewing multipotential stem cell in embryonic rat cerebral cortex. Nature 372: 263-266.

11. Emerson, S. G. 1991. The stem cell model of hematopoiesis. pp. 72-81. In: R. Hoffman et al. (eds.), Hematology: Basic principles and practice. Churchill Livingstone, New York.

12. FIDAP Manual. Version 7.0. 1993. Fluid Dynamics International, Evanston, IL.

13. Frangos, J. A., McIntire, L. V., Eskin, S. G. 1988. Shear stress induced stimulation of mammalian cell metabolism. Biotechnol. Bioeng. 32: 1053-1060.

14. Glacken, M. W., Adema, E., Sinskey, A. J. 1988. Mathematical descriptions of hybridoma culture kinetics: I. Initial metabolic rates. Biotechnol. Bioeng. 32: 491-506.

15. Gronthos, S., Simmons, P. J. 1995. The growth factor requirements of STRO-1-positive human bone marrow stromal precursors under serum-deprived conditions in vitro. Blood 85: 929-940.

16. Halberstadt, C. R., Hardin, R., Bezverkov, K., Snyder, D., Allen, L., Landeen, L. 1994. The in vitro growth of a three-dimensional human dermal replacement using a single-pass perfusion system. Biotechnol. Bioeng. 43: 740-746.

17. Hall, P. A., Watt, F. M. 1989. Stem cells: The generation and maintenance of cellular diversity. Development 106: 619-633.

18. Hubbell, J. A., McIntire, L. V. 1986. Platelet active concentration profiles near growing thrombi-A mathematical consideration. Biophys. J. 50: $937-945$

19. Hubbell, J. A., Palsson, B. O., Papoutsakis, E. T. (eds.). 1994. Special issue: Tissue Engineering and cell therapies. Biotechnol. Bioeng. 43(7/8).

20. Koller, M. R., Bender, J. G., Miller, W. M., Papoutsakis, E. T. 1993. Expansion of primitive human hematopoietic progenitors in a perfusion bioreactor system with IL-3, IL-6, and stem cell factor. Bio/Technology 11: 358-363.

21. Koller, M. R., Emerson, S. G., Palsson, B. O. 1993. Large-scale expansion of human stem and progenitor cells from bone marrow mononuclear cells in continuous perfusion cultures. Blood 82: 378-384.

22. Koller, M. R., Palsson, B. O. 1993. Tissue engineering: Reconstruction of human hematopoiesis ex vivo. Biotechnol. Bioeng. 42: 909-930.

23. Koslow, A. R., Stromberg, R. R., Friedman, L. I., Lutz, R. J., Hilbert, S. L., Schuster, P. 1986. A flow system for the study of shear forces upon cultured endothelial cells. J. Biomechan. Eng. 108: $338-341$.

24. Lackie, J. 1991. Adhesion from flow. p. 48. In: A. S. G. Curtis and J. M. Lackie (eds.), Measuring cell adhesion. Wiley, New York.

25. Langer, R., Vacanti, J. P. 1993. Tissue engineering. Science 260: 920-926.

26. Lansdorp, P. M., Dragowska, W. 1993. Maintenance of hematopoiesis in serum-free bone marrow cultures involves scquential recruitment of quiescent progenitors. Exper. Hematol. 21: 13211327.

27. Lauffenburger, D. A., Lindermann, J. J. 1993. Receptors: Models for binding, trafficking, and signaling. pp. 248-252. Oxford University Press, Oxford. 
28. Levesque, M. J., Nerem, R. M. 1985. The elongation and orientation of cultured endothelial cells in response to shear stress. J. Biomech. Eng. 107: 341-347.

29. Long, M. W., Max, S. W. (eds.). 1993. The hematopoietic microenvironment: The functional and structural basis of blood cell development. John Hopkins University Press, Baltimore, MD.

30. Lucas, P. A., Caplan, A. I. 1988. Chemotactic response of embryonic limb and mesenchymal cells and muscle-derived fibroblasts to transforming growth factor- $\beta$. Connective Tissue Res. 18: 1-7.

31. Matlab Manual. Version 4.2. 1994. MathWorks Inc., Natick, MA.

32. Metcalf, D. 1988. The molecular control of blood cells. Harvard University Press, Cambridge.

33. Monod, J. 1949. The growth of bacterial cultures. Annu. Rev. Microbiol. 3: 371-394.

34. Naughton, B. A., Naughton, G. K. 1989. Modulation of long-term bone marrow culture by stromal support cells. Ann. NY Acad. Sci. 554: $125-140$.

35. Naughton, B. A., Sibanda, B., Naughton, G. K. 1991. Long-term liver cell cultures as potential substrates for toxicity assessment. pp. 193-202. In: A. M. Goldberg (ed.), In vitro toxicology: Mechanisms and new technology. Mary Ann Liebert Publishers, New York.

36. Naughton, B. A. 1995. The importance of stromal cells. pp. 1710 1727. In: J. D. Bronzino (ed.), Biomedical engineering handbook. CRC Press, Boca Raton, FL.

37. Navsaria, H. A., Sexton, C., Bouvard, V., Leigh, I. M. 1994. Growth of keratinocytes with a 3T3 feeder layer: Basic techniques. pp. 5-12. In: I. M. Leigh and F. M. Watt (eds.), Keratinocyte methods. Cambridge University Press, Cambridge.

38. Nerem, R. M. 1992. Tissue engineering in the USA. Med. Biol. Eng. Comput. 30: CE8-12.

39. Nollert, M. U., Diamond, S. L., McIntire, L. V. 1991. Hydrodynamic shear stress and mass transport modulation of endothelial cell metabolism. Biotechnol. Bioeng. 38: 588-602.

40. Palsson, B. O., Hubbell, J. A. 1995. Tissue engineering. Chapter XI. In: J. D. Bronzino (ed.), Biomedical engineering handbook. CRC Press, Boca Raton, FL.

41. Palsson, B. O., Paek, S.-H., Schwartz, R. M., Palsson, M., Lee, G.-M., Silver, S., Emerson, S. G. 1993. Expansion of human bone marrow progenitor cells in a high cell density continuous perfusion system. Bio/Technology 11: 368-372.

42. Papanastasiou, T. C., Malamataris, N., Ellwood, K. 1992. A new outflow boundary condition. Int. J. Numer. Methods Eng. 14: 587-608.

43. Peng, C.-A. 1995. Hematopoietic tissue engineering: Effects of fluid dynamics and mass transfer on cell growth and migration. Ph.D. Dissertation. University of Michigan, Ann Arbor, MI.

44. Peng, C.-A., Palsson, B. O. 1995. Importance of non-homogeneous concentration distributions near walls in bioreactors for primary cell cultures. Ind. Eng. Chem. Res. 34: 3239-3245.

45. Potten, C. S., Loeffler, M. 1990. Stem cells: Attributes, cycles, spirals, pitfalls and uncertainties. Development 110: 1001-1020.

46. Potten, C. S., Loeffler, M. 1987. A comprehensive model of the crypts of the small intestine of the mouse provides insight into the mechanisms of cell migration and proliferation hierarchy. J. Theor. Biol. 127: 381-391.

47. Potten, C. S., Wichmann, H. E., Loeffler, M., Dobek, K., Major, D. 1982. Evidence for discrete cell kinetic subpopulations in mouse epidermis based on mathematical analysis. Cell Tissue Kinet. 15: $305-320$.
48. Rheinward, J. G., Green, H. 1975. Serial cultivation of strains of human epidermal keratinocytes: The formation of keratinizing colonies from single cells. Cell 6: 331-343.

49. Rheinward, J. G., Green, H. 1977. Epidermal growth factor and the multiplication of cultured human epidermal keratinocytes. Nature 265: 421-424.

50. Rinkes, I. H., Toner, M., Tompkins, R. G., Yarmush, M. L. 1994. An extracorporeal microscopy perfusion chamber for on-line studies of environmental effects on cultured hepatocytes. J. Biomech. Eng. 116(2): 135-139.

51. Savinell, J. M., Lee, G. M., Palsson, B. O. 1989. On the orders of magnitude of epigenic dynamics and monoclonal antibody production. Bioproc. Eng. 4: 231-234.

52. Schlichting, H. 1979. Boundary layer theory, 7 th edition. McGrawHill, New York

53. Schmitz, S., Franke, H., Brusis, J., Wichmann, H. E. 1993. Quantification of the cell kinetic effects of G-CSF using a model of human granulopoiesis. Exper. Hematol. 21: 755-760.

54. Sell, S. 1990. Is there a liver stem cell? Cancer Res. 50: 3811-3815.

55. Shah, R. A., London, A. L. 1978. Laminar flow forced convection in ducts. Adv. Heat Transfer (Suppl. 1). Academic, New York.

56. Sigal, S. H., Brill, S., Fiorino, A. S., Reid, L. M. 1992. The liver as a stem cell and lineage system. Am. J. Physiol. 263: G139-G148.

57. Silver, F. H. 1994. Biomaterials, medical devices, and tissue engineering: An integrated approach. Chapman \& Hall, London.

58. Skalak, R., Fox, C. F. (eds.). 1988. Tissue engineering. Liss, New York.

59. Stathopoulos, N. A., Hellums, J. D. 1985. Shear stress effects on human embryonic kidney cells in vitro. Biotechnol. Bioeng. 27: 1021-1026.

60. Stemple, D. L., Anderson, D. J. 1992. Isolation of a stem cell for neurons and glia from the mammalian neural crest. Cell 71: 973-985.

61. Thorgeirsson, S. S. 1993. Hepatic stem cells. Am. J. Pathol. 142: $1331-1333$.

62. Till, J. E., McCulloch, E. A., Siminovitch, L. 1964. A stochastic model of stem cell proliferation, based on the growth of spleencolony forming cells. Proc. Natl. Acad. Sci. USA 51: 29-36.

63. Usami S., Chen, H. H., Zhao, Y., Chien, S., Skalak, R. 1993. Design and construction of a linear shear stress flow chamber. Ann. Biomed. Eng. 21: 77-83.

64. van Kooten, T. G., Schakenraad, J. M., Van der Mei, H. C., Busscher, H. J. 1992. Development and use of a parallel-plate flow chamber for studying cellular adhesion to solid surfaces. J. Biomed. Mater. Res. 26: 725-738.

65. Warner, H. R., Athens, J. W. 1964. An analysis of granulocyte kinetics in blood and bone marrow. Ann. N.Y. Acad. Sci. 113: $523-536$

66. Wichmann, H. E., Loeffler, M., Schmitz, S. 1988. A concept of hemopoietic regulation and its biomathematical realization. Blood Cells 14: 411-429.

67. Wilkinson, P. C. 1982. Chemotaxis and inflammation, 2nd edition. Churchill Livingstone, London.

68. Wright, N. A. 1983. The cell proliferation kinetics of the epidermis. pp. 203-229. In: L. A. Goldsmith (ed.), Biochemistry and physiology of the skin. Oxford University Press, Oxford.

69. Yasumizu, C., Yasumizu, R., Toki, J., Asou, H., Nishino, T., Komatsu, Y., Ikehara, S. 1994. Production of hematopoietic stem cell-chemotactic factor by bone marrow stromal cells. Blood 83(4): 964-971

70. Young, M., Carroad, P., Bell, R. 1980. Estimation of diffusion coefficients of proteins. Biotechnol. Bioeng. 22: 947-955. 